\title{
Determinants for Bullying Victimization among 11-16-Year-Olds in 15 Low- and Middle-Income Countries: A Multi-Level Study
}

\section{Michael L. Wilson ${ }^{1,2, *}$, Andrea C. Dunlavy ${ }^{1}$ and André Berchtold ${ }^{3}$}

1 Centre for Injury Prevention and Community Safety (CIPCS), PeerCorps Trust Fund, 352/64 Makunganya Street, Co-Architecture Building, $4^{\text {th }}$ Floor, P. O. Box 22499, Dar es Salaam, Tanzania; E-Mail: andrea.dunlavy@peercorpstrust.org

2 Unit of Adolescent Psychiatry, Turku University Hospital, Department of Adolescent Psychiatry, University of Turku, Kaskenkatu 13 A 7, Turku 20700, Finland

3 Institute of Social Sciences, University of Lausanne, SSP/Géopolis, Lausanne CH-1015, Switzerland; E-Mail: andre.berchtold@unil.ch

* Author to whom correspondence should be addressed; E-Mail: michael.wilson@peercorpstrust.org; Tel.: +255-754-636963.

Received: 12 June 2013; in revised form: 1 October 2013 / Accepted: 9 October 2013 /

Published: 17 October 2013

\begin{abstract}
Bullying is an issue of public health importance among adolescents worldwide. The present study aimed at explaining differences in bullying rates among adolescents in 15 low- and middle-income countries using globally comparable indicators of social and economic well-being. Using data derived from the Global School-based Health Survey, we performed bivariate analyses to examine differences in bullying rates by country and by bullying type. We then constructed a multi-level model using four fixed variables (age, gender, hunger and truancy) at the individual level, random effects at the classroom and school levels and four fixed variables at the country level (Gini coefficient, per capita Gross Domestic Project, homicide rate and pupil to teacher ratio). Bullying rates differed significantly by classroom, school and by country, with Egypt (34.2\%) and Macedonia (3.6\%) having the highest and lowest rates, respectively. Eleven-year-olds were the most likely of the studied age groups to report being bullied, as was being a male. Hunger and truancy were found to significantly predict higher rates of bullying. None of the explanatory variables at the country level remained in the final model. While self-reported bullying varied significantly between countries, the variance between classrooms better
\end{abstract}


explained these differences. Our findings suggest that classroom settings should be considered when designing approaches aimed at bullying prevention.

Keywords: violence; aggression; secondary schools; hunger; adolescents

\section{Introduction}

Bullying has risen to become one of the most important forms of interpersonal violence among adolescents worldwide [1]. Defined as a wide spectrum of aggressive actions toward one or more individuals repeatedly and over time, bullying can have several adverse health effects if ignored [2,3]. For example, adolescents who are bullied demonstrate poorer psycho-social adjustment, increased difficulty in making and retaining friends and are more likely to feel lonely within their peer groups [4]. These harms may extend to deeper internalizing disorders, such as low self-esteem, and externalizing behaviors, such as self-harm [5]. Those who are bullied in school have higher rates of truancy and are more likely to avoid school the more they are bullied [6]. Prior research has also revealed that these psycho-social struggles can endure into adulthood, where they may consequently generate additional problems in work and family life [7,8].

While bullying exists in most countries, considerable variations in prevalence exist. Within high-income country (HIC) settings, bullying prevalence ranges from a low of 5.3/6.5\% (males/females) in Hungary, to $36.3 / 32.3 \%$ in Lithuania for a reference period of " $2-3$ times per month during the past couple of months" [9]. In the low- and middle-income countries (LMIC), which collect population-based data, differences range from $8.2 / 7.3 \%$ in Tajikistan to $63.1 / 57.7 \%$ in Zambia for students who reported being bullied at least once during a one month period [1]. According to the most recent data, variations in bullying prevalence across countries may be partially explained by socioeconomic inequalities, which differ between them $[9,10]$. One theory is that as inequalities widen, increasing pressures are placed on pre-existing social controls over individual and collective behavior. The social cohesion that once buffered against interpersonal conflict may no longer serve to protect against it $[11,12]$. Rapid growth and unplanned urbanization in LMICs are other reasons that have exacerbated the rise of inequalities [13].

Most of the available literature on bullying among adolescents tends to focus on those from HIC settings. Additionally, the large share of research on bullying in LMICs is limited to analyses of proximate factors at the individual level. Few studies exist among LMICs that examine the contribution of contextual factors, which may explain why differences between countries exist [11]. The aim of this study lies in explaining bullying differences among LMICs by using globally comparable indicators of social and economic well-being in addition to school and individual level factors.

\section{Methods}

\subsection{Data}

The data for this study were derived from global school-based health surveys (GSHS) completed during 2006-2008. The GSHS, representing more than 40 LMICs, measures behavioral risk and 
protective factors among school-attending adolescents. More detailed information on the GSHS can be found elsewhere [14]. The GSHS data were sampled in a two-stage framework beginning at the school level. In each country, schools were randomly selected to provide a representative sample of adolescents aged 11-16 years from the entire country or large urban areas. Then, classrooms were selected within each school. Depending on the country, either all classrooms of the selected schools or only a subset of them were included in the survey. Data from 15 LMICs were included in our analyses (see Table 1). Two were limited to cities within countries (Dar es Salaam in Tanzania and Quito in Ecuador). Other country datasets were not considered for inclusion, because they excluded key comparison variables (not all countries use the same core questions of the GSHS), such as truancy. On the other hand, we chose not to include two variables (to have considered suicide, to have planned suicide), because they were not available in several of the 15 countries under study.

Table 1. Bivariate analyses of bullied adolescents among a sample of low- and middle-income countries (2006-2008).

\begin{tabular}{|c|c|c|c|}
\hline Characteristics & $N=33,502$ (weighted data) & $\%$ Bullied $(n=6,383)$ & $p$-value \\
\hline \multicolumn{4}{|l|}{ Age (years) } \\
\hline 11 & 346 & 24.6 & 0.153 \\
\hline 12 & 2,945 & 20.2 & - \\
\hline 13 & 7,426 & 20.2 & - \\
\hline 14 & 8,415 & 19.7 & - \\
\hline 15 & 7,976 & 17.0 & - \\
\hline 16 & 6,394 & 18.6 & - \\
\hline Gender & & & $<0.001$ \\
\hline Male & 16,631 & 21.3 & - \\
\hline Female & 16,871 & 16.8 & - \\
\hline Truancy & & & $<0.001$ \\
\hline 0 days & 22,346 & 15.3 & - \\
\hline 1 or 2 days & 7,578 & 22.7 & - \\
\hline 3 to 5 days & 2,115 & 34.6 & - \\
\hline 6 to 9 days & 777 & 34.2 & - \\
\hline 10 or more days & 686 & 35.2 & - \\
\hline Hunger & & & $<0.001$ \\
\hline Never & 16,141 & 13.9 & - \\
\hline Rarely & 7,562 & 20.8 & - \\
\hline Sometimes & 7,614 & 24.0 & - \\
\hline Most of the time & 1,321 & 32.4 & - \\
\hline Always & 863 & 36.0 & \\
\hline Country & & & $<0.001$ \\
\hline Argentina & 4,237 & 11.6 & - \\
\hline Ecuador (Quito) & 166 & 8.1 & - \\
\hline Egypt & 5,248 & 34.2 & - \\
\hline Ghana & 1,902 & 33.9 & - \\
\hline Jordan & 669 & 18.3 & - \\
\hline
\end{tabular}


Table 1. Cont.

\begin{tabular}{lccc}
\hline Characteristics & $\boldsymbol{N}=\mathbf{3 3 , 5 0 2}$ (weighted data) & $\mathbf{\%}$ Bullied $(\boldsymbol{n}=\mathbf{6 , 3 8 3})$ & $\boldsymbol{p}$-value \\
\hline Macedonia & 237 & 3.6 & - \\
Morocco & 2,730 & 10.3 & - \\
Philippines & 8,659 & 21.2 & - \\
St. Lucia & 16 & 14.5 & - \\
Tanzania (Dar es & 319 & 11.3 & - \\
Salaam) & & & - \\
Thailand & 6,120 & 10.3 & - \\
Trinidad & 188 & 9.0 & - \\
Tunisia & 1,282 & 12.4 & - \\
Uruguay & 202 & 8.1 & - \\
Yemen & 1,527 & 21.5 & - \\
\hline
\end{tabular}

Significant differences in the proportions of bullied $v s$. non-bullied participants are indicated by $p$-values.

It is important to note that the number of included students ranged from 769 (Yemen) to 4,562 (Ghana), but that a correct analysis of cross-national data requires taking into account the relative population size in each country. As such, all analyses were made using weighted data. Thus, the values appearing in the country part of Table 1 reflect the relative share of the total population living in each country. For instance, 1,073 students out of 33,502 were surveyed in St. Lucia, but in terms of weighted data, these students represented only 16 persons, that is, $0.05 \%$ of the total sample.

In this study, we made comparisons across countries between bullying and several socio-demographic and contextual variables based on indications in the literature. At the time of data collection, ethical approval had been provided by the ministries of education and/or health in each participating country. All data were freely available via the GSHS website [14].

\subsection{Participants}

A total of $n=33,502$ school-attending adolescents belonging to 493 classrooms and 281 different schools were included in the present study. The set of weights provided within each original GSHS dataset were used in order to keep, as accurate as possible, the structure of the population under study. The sum of the weights was normalized to the number of participants in the study.

\subsection{Variable Selection (Dependent Variable)}

We defined bullying as having been subjected to at least three bullying incidents during one or more days within the 30 day period prior to the survey. A seven item question in the GSHS survey considered the following forms of bullying: (1) "I was hit, kicked, pushed, shoved around or locked indoors"; (2) "I was made fun of because of my race or color"; (3) "I was made fun of because of my religion"; (4) "I was made fun of with sexual jokes, comments or gestures"; (5) "I was left out of activities on purpose or completely ignored"; (6) "I was made fun of because of how my body or face looks"; (7) "I was bullied in some other way". We provide the response items for each country in Table 2. Those not reporting any of the above forms of bullying served as the reference group (defined in the tables as "ref"). 
Table 2. Country values by bullied category among a sample of adolescents in low- and middle-income countries (2006-2007).

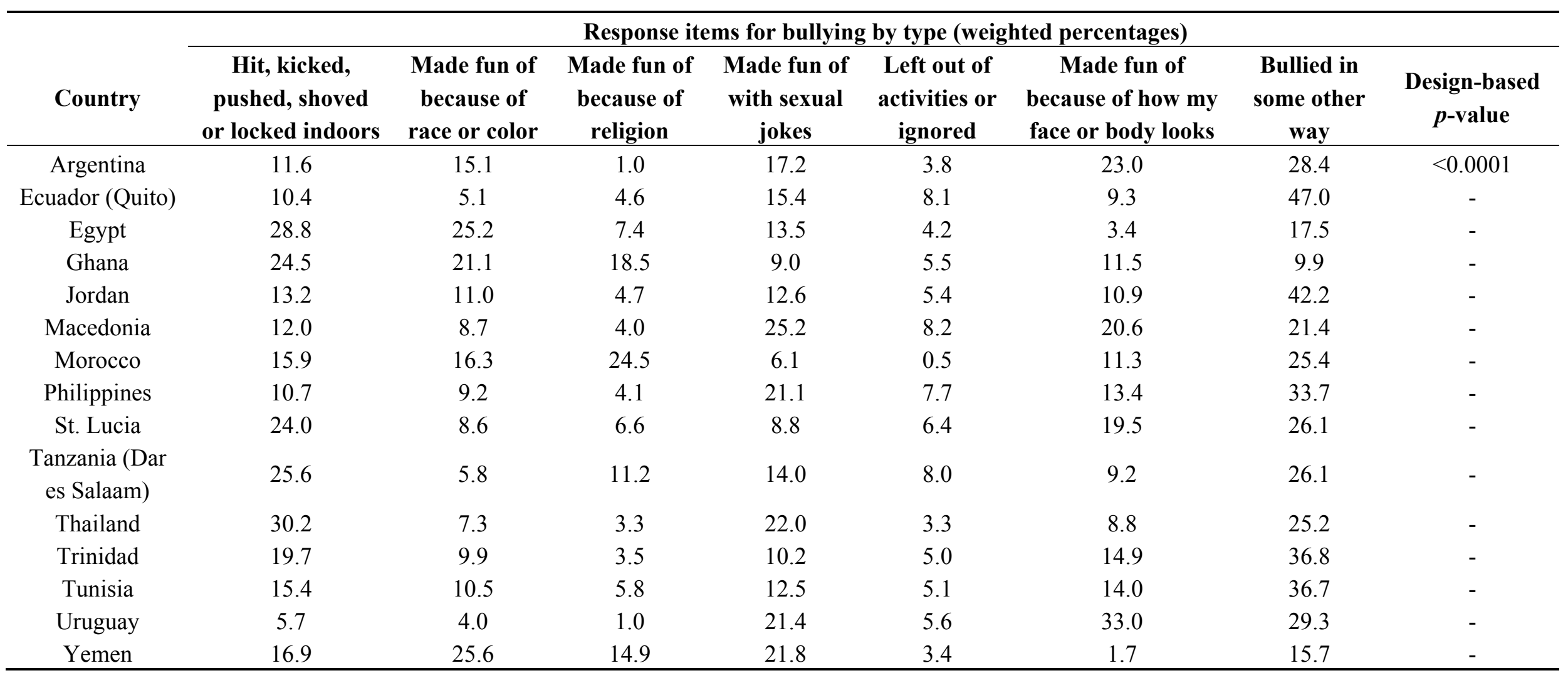




\subsection{Individual-Level Variables}

We selected several fixed explanatory variables at both the individual and country levels that were consistent with our aim, but no fixed variable was available at the intermediary levels (classroom and school). At the individual level, in addition to socioeconomic status (SES) [15], prior research suggested that bullying was associated with truancy, that younger pupils were more vulnerable and that boys were often overrepresented $[6,16,17]$. In order to explore these associations as closely as possible, we derived our variables from the following questions in the GSHS surveys:

Age in years (11-16) was used along with gender. We examined the effect of not having enough food in the home (hunger) by using the responses to the question: "During the past 30 days, how often did you go hungry because there was not enough food in your home?" The responses were "never", "rarely", "sometimes", "most of the time" or "always". For truancy, we used the responses from the question: "During the past 30 days, on how many days did you miss classes or school without permission?". The responses were "never", "1 or 2 days", "3 to 5 days", "6 to 9 days" or "10 days or more".

\subsection{Country-Level Variables}

At the country-level, we considered four independent variables, with their relevance being based on prior research [10,18]. The first two were measures of economic equality within and between countries, the Gini coefficient (GC) and the per capita Gross Domestic Product (GDP). The GC is a measure of statistical dispersion, which measures the inequality among values of a frequency distribution, such as income. A coefficient of zero expresses perfect equality or that everyone within a country has roughly the same income. A coefficient of 100 expresses maximal inequality or that one person has all of the income within a country [19]. The GDP refers to the market value of final goods and services produced within a country within a given period. The GDP per capita, as used in this study, is often considered an indicator of a country's overall standard of living [20].

The second two variables were used as proxies for social equality between countries. The first considered the ratio of secondary school pupils to secondary school teachers, which informs about the allocation of available resources to education in a given country [21]. Classrooms with a very high pupil to teacher ratio have been found to be disruptive to education, as it is related to suboptimal levels of supervision [22]. The second variable used was the annual rate of intentional homicides per 100,000 persons. Research shows that countries with high rates of homicide are more likely to have exacerbated levels of social inequality [23]. Additionally, in settings where interpersonal violence is widespread, adolescents are more likely to demonstrate increased aggression towards others [24]. We provide detailed values for each country in Table 3. All four variables were derived from World Bank development indicators [25].

\subsection{Random Effects}

In addition to all previously described fixed effects, random effects were also considered for inclusion in the multilevel model. Random effects allow the effect of an explanatory factor at a given level to vary in the function of the value of a higher level. Moreover, this approach indicates which 
part of the total variability is attributable to each part of the model [26]. Here, we tried to introduce each of the four individual-level factors at the classroom, school and country levels. For instance, a significant random effect for gender at the country level would signify that the relationship between being a boy and being bullied is different from one country to another.

\subsection{Data Analysis}

Bivariate analyses between individual-level factors and bullying were carried out using Pearson's chi-square, taking into account the multilevel design of the survey. Since the number of observations included in the dataset was large, we set the threshold for statistical significance at $p<0.01$. Then, following the strategy defined by Hox, 1994 [27], we constructed a multilevel model, the first level being a logistic regression predicting the fact of having been bullied. First, we tested the usefulness of all four hierarchical levels. Then, we included successively fixed explanatory factors at the individual level, random effects, fixed explanatory factors at the country level and cross-level interactions. All numeric variables were standardized before inclusion in the model. All computed models were compared using the Bayesian Information Criterion (BIC), which considers both the quality of adjustment of the model to the data and the parsimony of the model [28]. The different effects were introduced one at a time in the model, and only those effects showing a significant improvement of the BIC were retained. Fixed effects are interpreted similarly as in a standard regression model. Random effects, when significant, imply that the effect of an explanatory variable is not homogeneous, but that it varies among the levels of another variable. For instance, a significant effect of the random factor, gender, at the classroom level implies that the exact effect of being a female or a male can vary from one classroom to another. We report effect measures as odds ratios (OR) along with $99 \%$ confidence intervals (CIs). All analyses were performed using the R Statistical Environment [29].

\section{Results}

In the bivariate analyses (Table 1), we found that bullying was significantly associated with being male, truancy and poverty. Although bullying decreased with age, the differences were not statistically significant. The prevalence of bullying significantly differed between countries, ranging from a low of $3.6 \%$ in Macedonia to a high of $34.2 \%$ in Egypt.

When examining rates by bulling type (Table 2), we found that physical assaults were the most common form of bullying among students in Egypt (28.8\%) and Ghana (24.5\%) and making fun because of one's race or color was the most common form of bullying in Yemen (25.6\%). In all other countries, the reported rates of unspecified forms of bullying (i.e., bullied in some other way) were higher than all the other categories.

In Table 3, we show the country-level variables that were included in the analyses. Egypt had the most equitable distribution of income $(\mathrm{GC}=32.14)$ and Ecuador (Quito) had the lowest equity in absolute terms $(\mathrm{GC}=53.65)$. The Philippines had the highest secondary school student to teacher ratio (32.3), while Argentina had the lowest (12.6). Egypt had the lowest rate of intentional homicide per 100,000 persons (0.3), and Tanzania had the highest among all of the settings considered (26.0). The country with the highest GDP per capita was Trinidad, with 21,000 USD, and the lowest was Tanzania, with 1,400 USD. 
Table 3. Country values included in the analyses of bullied vs. non-bullied adolescents among a sample of low- and middle-income countries (2006-2008). GC, Gini coefficient.

\begin{tabular}{ccccc}
\hline Country & GC (Year†) & $\begin{array}{c}* \text { Pupil to } \\
\text { teacher ratio } \\
\text { (Year } \$ \text { ) }\end{array}$ & $\begin{array}{c}* \text { Intentional } \\
\text { homicide rate per } \\
\mathbf{1 0 0 , 0 0 0} \text { (Year } \$)\end{array}$ & $\begin{array}{c}\text { GDP per capita } \\
\text { (USD) }\end{array}$ \\
\hline Argentina & 48.77 & $12.6(2006)$ & $5.5(2007)$ & 14700 \\
Ecuador (Quito) & 53.65 & $14.4(2006)$ & $18.5(2006)$ & 7800 \\
Egypt & 32.14 & $17.1(2004)$ & $0.3(2006)$ & 6200 \\
Ghana & 42.76 & $19.7(2006)$ & $12.8(2006)$ & 2500 \\
Jordan & 37.72 & $17.9(2003)$ & $6.8(2006)$ & 5400 \\
Macedonia & 44.2 & $14.7(2005)$ & $5.2(2006)$ & 9700 \\
Morocco & 40.88 & $18.7(2004)$ & $1.1(2006)$ & 4800 \\
Philippines & 44.04 & $32.3(2006)$ & $7.6(2006)$ & 3500 \\
St. Lucia & 42.58 & $17.0(2006)$ & $19.0(2006)$ & 11200 \\
Tanzania (Dar es & 37.58 & $17.4(1995)$ & $26.0(2006)$ & 1400 \\
Salaam) & 42.45 & $21.7(2006)$ & $6.8(2006)$ & 8700 \\
Thailand & 40.27 & $14.0(2007)$ & $13.8(2006)$ & 21200 \\
Trinidad & 40.81 & $16.9(2006)$ & $1.5(2006)$ & 9400 \\
Tunisia & 46.24 & $15.4(2006)$ & $6.0(2006)$ & 13700 \\
Uruguay & 37.69 & $24.6(2003)$ & $3.2(2006)$ & 2700 \\
Yemen &
\end{tabular}

* Figures rounded to nearest tenth; $\uparrow$ values reflect the 2003-2008 period depending on data availability; $\$$ values reflect the most recent year prior to survey completion for which data were available.

Regarding the multilevel model, we first tested each of the four levels of the data structure (individual, classroom, school, country). However, none of the levels appeared to be statistically non-significant, so we retained all of them. All fixed individual factors were retained in the final model. Even if not statistically significant at the bivariate level, age was also included as a controlled continuous factor. On the other hand, factors at the country level were rejected, as well as all cross-level interactions. Finally, two random effects (gender and hunger) remained at the classroom level. Table 4 summarizes the fixed part of the model. Females were less likely to report being bullied overall. Reported bullying victimization appeared to slightly decrease with age, but the association did not reach significance. Pupils from poorer households reported being bullied more often, as were those who were truant. Regarding random effects (Table 5), we first see that since random effects are present at each level of the model, the fact of being bullied is not only an individual level characteristic of the students, but also a matter of context: being in a particular classroom, a particular school or a particular country also has an influence upon the probability of being bullied. All these effects can even be additive, so a particularly unlucky student attending a particular school could have a high probability of being bullied, even if he or she lives in a country where the overall level of bullying is low. Moreover, we found that the effect of being bullied by gender and by level of reported hunger differed significantly from one classroom to another, so poor students, for instance, can have a different probability of being bullied, depending on to which classroom they are assigned. 
Table 4. Fixed variables that explain differences in bullying at the individual level among 15 low- and middle-income countries (2006-2008). OR, odds ratios; CI, confidence interval.

\begin{tabular}{cccc}
\hline Variable & Category & $\begin{array}{c}\text { OR } \\
(\mathbf{9 9 \%} \mathbf{C I})\end{array}$ & $\boldsymbol{p}$-value \\
\hline Age (continuous) & - & $0.97(0.94-1.00)$ & 0.025 \\
Gender (ref: male) & Female & $0.73(0.65-0.82)$ & $<0.001$ \\
Went hungry (ref: never) & Rarely & $1.61(1.39-1.86)$ & $<0.001$ \\
& Sometimes & $1.95(1.71-2.22)$ & $<0.001$ \\
& Most of the time & $2.40(1.97-2.92)$ & $<0.001$ \\
& Always & $2.93(2.39-3.58)$ & $<0.001$ \\
Truancy (ref: never) & 1 or 2 days & $1.31(1.22-1.41)$ & $<0.001$ \\
& 3 to 5 days & $2.46(2.20-2.75)$ & $<0.001$ \\
& 6 to 9 days & $2.20(1.84-2.62)$ & $<0.001$ \\
& 10 or more days & $3.14(2.60-3.79)$ & $<0.001$ \\
\hline
\end{tabular}

Table 5. Random effects model for variables that explain differences in bullying rates among 15 low- and middle income countries (2006-2008).

\begin{tabular}{cccc}
\hline Level & Variable & Category & Variance \\
\hline Classroom & Intercept & - & 0.5665 \\
Classroom & Gender (ref: male) & Female & 0.4019 \\
Classroom & Went hungry (ref: never) & Rarely & 0.8373 \\
Classroom & & Sometimes & 0.5262 \\
Classroom & & Most of the time & 0.7723 \\
Classroom & & Always & 0.4419 \\
School & & - & 0.0693 \\
Country & Intercept & - & 0.3419 \\
\hline
\end{tabular}

\section{Discussion}

This study examined differences in the rates of reported bullying among adolescents across LMICs. It used general and globally comparable indicators of social and economic well-being. In the bivariate and multi-level analyses, we found that age, gender, hunger and truancy explained bullying at the individual level, which mirrored findings in the literature [6,16,30,31]. In addition to significant variations in bullying rates by country, the types of bullying reported within countries also differed significantly (see Table 2). However, we noted that in a majority of the countries under study, the number of reports of bullying victimization (bullied in some other way) was disproportionately higher than in all of the preceding categories. One explanation may lie in the absence of a question that might have captured other forms of bullying, such as cyber bullying, which has also been reported in LMIC settings [32].

In the random part of the model (see Table 5), we noted that at the classroom level, gender and hunger were significant factors in explaining differences in bullying between classrooms. Previous research has documented that bullying rates were significantly higher in co-educational schools and in all male schools compared with female only schools [33]. Unfortunately, owing to limitations in the data, it was not possible to further examine this in the present study. Concerning the variable, hunger, 
previous research asserts that bullied students were more likely to be from more deprived areas of society [30,34]. However, hunger used alone in analyses as a measure of deprivation may not necessarily be a particularly sensitive indicator of relative poverty [35].

None of the selected country-level variables were able to explain bullying differences between countries, even if the country random effect indicated that there were differences. In a previous study based on data from mainly high-income settings, the authors also concluded that neither GDP nor GC were able to explain bullying differences among HICs [9]. With regard to the variable, homicide rate, despite the potential role that community violence has in influencing victimizing behavior among adolescents, its effects at the individual level are possibly attenuated by other factors, such as family and peer influences [36]. Pupil to teacher ratio, while linked previously with, as a modifier of bullying victimization, school size, may have been a confounding factor according to other research [37]. However, limitations inherent in the data prevented confirmatory analyses.

A strength of this study includes its use of data from a standardized survey and its comparison of bullying victimization prevalence across 15 LMIC settings. The sample sizes in each country were large enough to allow for the detection of statistically valid associations. However, we present these results in light of their limitations, which include the use of self-reported data. All questionnaire items were subjected to extensive piloting and validation, yet the possibility of biased reporting due to social desirability, even in anonymous questionnaires, has been deemed plausible [38].

The study's cross-sectional design limits the ability to examine causal relationships and, as a result, the analyses presented here should be viewed as exploratory in the absence of longitudinal data. Because these findings were based upon in school samples only, they will not be representative of adolescents outside of school environments, who may be at increased risk for bullying. The study's limited age range also fails to allow for an appreciation of bullying phenomena, which may be influenced by factors that occurred before adolescence and have psychosocial sequelae, which may persist long after [39]. While two non-nationally representative population samples were included (Quito and Dar es Salaam), their inclusion was considered important, owing to the current paucity of school-based data on bullying in those regions.

\section{Conclusions}

While self-reported bullying varied significantly between countries, the peculiarities inherent in the classroom environment were better able to explain differences between bullied and non-bullied adolescents. Gender and hunger as factors, while not homogeneously related to bullying, have an effect that can vary from one classroom to another, even in the same country. The present findings suggest that classroom settings may be important environments to take into account when designing approaches that target bullying prevention in schools. These interventions, for example, may include encouraging healthy peer relationships or developing educational programming on age-appropriate strategies for conflict resolution. Ultimately, more research is needed in order to determine what specific factors inherent in the classroom environment might influence bullying behavior. 


\section{Acknowledgments}

The authors would like to thank the Centers for Disease Control and Prevention (Atlanta, USA); and the World Health Organization (Geneva, Switzerland). We would also like to thank all the survey officers, country administrators and students who took part in the study. The first author's participation was supported by a grant from Suomen Kulttuurirahasto (Helsinki, Finland).

\section{Conflicts of Interest}

The authors declare no conflict of interest.

\section{References}

1. Lila C. Fleming, and Kathryn H. Jacobsen. "Bullying among middle-school students in low and middle income countries." Health Promotion International 25 (2010): 73-84.

2. Holan Liang, Alan J. Flisher, and Carl J. Lombard. "Bullying, violence, and risk behavior in South African school students." Child Abuse \& Neglect 31 (2007): 161-71.

3. Dan Olweus. "Bullying at school. Basic facts and an effective intervention programme." Promot \& Education 1 (1994): 27-31, 48.

4. Tonja R. Nansel, Mary Overpeck, Ramani S. Pilla, June W. Ruan, Bruce Simons-Morton, and Peter Scheidt. "Bullying behaviors among US youth: Prevalence and association with psychosocial adjustment.” Journal of the American Medical Association 285 (2001): 2094-2100.

5. Yulan Cheng, Ian M. Newman, Ming Qu, Lazarous Mbulo, Yan Chai, Yan Chen, and Duane F. Shell. "Being bullied and psychosocial adjustment among middle school students in China." Journal of School Health 80 (2010): 193-99.

6. Rachel C. Vreeman, and Aaron E. Carroll. "A systematic review of school-based interventions to prevent bullying." Archives of Pediatrics and Adolescent Medicine 161 (2007): 78-88.

7. Kaj Björkqvist, Karin Osterman, and Petra Berg. "Higher rates of victimization to physical abuse by adults found among victims of school bullying." Psychological Reports 109 (2011): 167-68.

8. Howard Meltzer, Panos Vostanis, Tamsin Ford, Paul Bebbington, and Michael S. Dennis. "Victims of bullying in childhood and suicide attempts in adulthood." European Psychiatry 26 (2011): 498-503.

9. Pernille Due, Juan Merlo, Yossi Harel-Fisch, Mogens T. Damsgaard, Bjørn E. Holstein, Jørn Hetland, Candace Currie, Saoirse N. Gabhainn, Margarida G. de Matos, and John Lynch. "Socioeconomic inequality in exposure to bullying during adolescence: A comparative, cross-sectional, multilevel study in 35 countries." American Journal of Public Health 99 (2009): 907-14.

10. Pernille Due, Mogens T. Damsgaard, Rikke Lund, and Bjørn E. Holstein. "Is bullying equally harmful for rich and poor children?: A study of bullying and depression from age 15 to 27 ." European Journal of Public Health 19 (2009): 464-69.

11. Etienne G. Krug, James A. Mercy, Linda L. Dahlberg, and Anthony B. Zwi. "The world report on violence and health." The Lancet 360 (2002): 1083-88. 
12. Margie Peden, Kayode Oyegbite, Joan Ozanne-Smith, Adnan A. Hyder, Christine Branche, AKM F. Rahman, Frederick Rivara, and Kidist Bartolomeos. "World report on child injury prevention." Available online: http://www.who.int/violence_injury_prevention/child/injury/world_report/en/ (accessed on 3 December 2012).

13. Rait Ram. "Population increase, economic growth, educational inequality, and income distribution: Some recent evidence.” Journal of Development Economics 14 (1984): 419-28.

14. CDC. "CDC Global School-based Student Health Survey (GSHS)." Available online: http://www.cdc.gov/GSHS/ (accessed on 10 April 2012).

15. Young S. Kim, W. T. Boyce, Yun-Joo Koh, and Bennett L. Leventhal. "Time trends, trajectories, and demographic predictors of bullying: A prospective study in Korean adolescents." Journal of Adolescent Health 45 (2009): 360-67.

16. Billie Gastic. "School truancy and the disciplinary problems of bullying victims." Educational Review 60 (2008): 391-404.

17. Kirsti Kumpulainen, Eila Räsänen, and Irmeli Henttonen. "Children involved in bullying: Psychological disturbance and the persistence of the involvement." Child Abuse \& Neglect 23 (1999): 1253-62.

18. Michael Lynch. "Consequences of children's exposure to community violence." Clinical Child and Family Psychology Review 6 (2003): 265-74.

19. Corrado Gini. "Variabilità e mutabilità (Variability and Mutability)." Reprinted in Memorie di Metodologica Statistica. Edited by E. Pizetti and T. Salvemini. Rome: Libreria Eredi Virgilio Veschi, 1955.

20. Juliet N. Orem, Joses M. Kirigia, Robert Azairwe, Ibrahim Kasirye, and Oladapo Walker. "Impact of malaria morbidity on gross domestic product in Uganda." International Archives of Medicine 5 (2012): 12 .

21. Kristine Lykens, Karan P. Singh, Elewichi Ndukwe, and Sejong Bae. "Social, economic, and political factors in progress towards improving child survival in developing nations." Journal of Health Care for the Poor and Underserved 20 (2009): 137-48.

22. Wendy M. Craig, Debra Pepler, and Rona Atlas. "Observations of bullying in the playground and in the classroom." School Psychology International 21 (2000): 22-36.

23. Luiz A. C. Viana, Maria da Conceição N. Costa, Jairnilson S. Paim, and Ligia M. Vieira-da-Silva. "Social inequalities and the rise in violent deaths in Salvador, Bahia State, Brazil: 2000-2006." Caderdnos de Saúde Pública 27, Suppl. 2 (2011): S298-S308.

24. Deborah Gorman-Smith, and Patrick Tolan. "The role of exposure to community violence and developmental problems among inner-city youth." Devlopmental Psychopathology 10 (1998): 101-16.

25. World Bank World Development Indicators. "Data.” Available online: http://data.worldbank.org/ data-catalog/world-development-indicators (accessed on 24 March 2012).

26. André Berchtold. "Key elements in the statistical analysis of surveys." International Journal of Public Health 52 (2007): 117-19.

27. Joop J. Hox. Applied Multilevel Analysis. Amsterdam: TT-Publikaties, 1994.

28. Adrian Raftery. "Bayesian Model Selection in Social Research (with discussion)." In Sociological Methodology. Edited by Peter V. Marsden. Cambridge: Blackwells, 1995, 111-63. 
29. R Development Core Team. R: A Language Environment for Statistical Computing. Vienna: $\mathrm{R}$ Foundation for Statistical Computing, 2011.

30. Wendy Craig, Yossi Harel-Fisch, Haya Fogel-Grinvald, Suzanne Dostaler, Jorn Hetland, Bruse Simons-Morton, Michal Molcho, Margarida G. de Mato, Mary Overpeck, Pernille Due, and William Pickett. "A cross-national profile of bullying and victimization among adolescents in 40 countries." International Journal of Public Health 54 (2009): 216-24.

31. Konstantina Magklara, Petros Skapinakis, Tatiana Gkatsa, Stefanos Bellos, Ricardo Araya, Stylianos Stylianidis, and Venetsanos Mavreas. "Bullying behaviour in schools, socioeconomic position and psychiatric morbidity: A cross-sectional study in late adolescents in Greece." Child and Adolescent Psychiatry and Mental Health 6 (2012): 8.

32. Jorge del Río-Pérez, Xavier Bringué, Charo Sádaba, and Diana González. "Cyberbullying: Un análisis comparativo en estudiantes de Argentina, Brasil, Chile, Colombia, México, Perú y Venezuela." Available online: http://dspace.si.unav.es/dspace/handle/10171/17800 (accessed on 19 December 2012).

33. Enrique Chaux, Andrés Molano, and Paola Podlesky. "Socio-economic, socio-political and socio-emotional variables explaining school bullying: A country-wide multilevel analysis." Aggressive Behavior 35 (2009): 520-29.

34. Jaana Juvonen, Sandra Graham, and Mark A. Schuster. "Bullying among young adolescents: The strong, the weak, and the troubled." Pediatrics 112 (2003): 1231-37.

35. Jayanta Bhattacharya, Janet Currie, and Steven Haider. "Poverty, food insecurity, and nutritional outcomes in children and adults." Journal of Health Economics 23 (2004): 839-62.

36. Mona Khoury-Kassabri, Rami Benbenishty, Ron A. Astor, and Anat Zeira. "The contributions of community, family, and school variables to student victimization." American Journal of Community Psychology 34 (2004): 187-204.

37. Catherine P. Bradshaw, Anne L. Sawyer, and Lindsey M. O'Brennan. "A social disorganization perspective on bullying-related attitudes and behaviors: The influence of school context." American Journal of Community Psychology 43 (2009): 204-20.

38. Heba Alwan, Bharathi Viswanathan, Fred Paccaud, and Pascal Bovet. "Is accurate perception of body image associated with appropriate weight-control behavior among adolescents of the seychelles.” Journal of Obesity 2011 (2011): 817242.

39. Riittakerttu Kaltiala-Heino, and Sari Fröjd. "Correlation between bullying and clinical depression in adolescent patients." Adolescent Health, Medicine and Therapeutics 2 (2011): 37-44.

(C) 2013 by the authors; licensee MDPI, Basel, Switzerland. This article is an open access article distributed under the terms and conditions of the Creative Commons Attribution license (http://creativecommons.org/licenses/by/3.0/). 